\title{
MIGRAÇÕES INTRATERRITÓRIO: UMA ANÁLISE DOS FATORES INFLUENTES NA PERSPECTIVA DOS CONCLUINTES DO ENSINO MÉDIO DO DISTRITO DE GUAMIRIM EM IRATI-PR
}

\author{
INTRA-TERRITORY MIGRATION: AN ANALYSIS FROM \\ THE PERSPECTIVE OF HIGH SCHOOL STUDENTS \\ FROM THE DISTRICT OF GUAMIRIM IRATI-PR
}

\author{
Haroldo José Andrade Mathias* \\ Zaqueu Luis Bobato
}

\begin{abstract}
RESUMO
A atual conjuntura demográfica ampliou a importância da migração e evidenciou, sobretudo, a importância desta dinâmica populacional em suas relações com o aspecto social, econômico, político, cultural e até mesmo subjetivo, o que desperta o interesse pelas determinantes do êxodo rural. Embora o referencial teórico aponte um declínio quantitativo dessa modalidade migratória, ela ainda persiste quando determinados perfis populacionais são considerados. Dessa forma, verificar com os concluintes do ensino médio do Colégio Estadual do Campo Nossa Senhora de Fátima, no Distrito de Guamirim, em Irati-PR, quais os principais fatores que impulsionam à migração engendra uma perspectiva mais específica para analisar a temática, revelando nuances atenuadas em análises de escala mais abrangente. Os resultados obtidos com os questionários aplicados aos alunos aduzem que para o caso pesquisado variáveis como a intenção de prosseguir estudando, localização geográfica associada a condições das estradas e dos transportes e a oferta de trabalho têm forte influência na dinâmica migratória. Outros fatores, relevantes quando inter-relacionados, podem ser entendidos como o pano de fundo que compõem o contexto dos alunos e da localidade, como os aspectos culturais, étnicos, históricos, além de fatores de ordem psicológica ou subjetiva, ratificando a complexidade e a especificidade dos determinantes desta dinâmica (e dos reflexos que dialeticamente ela gera), dificultando que explicações lineares de causa e efeito, generalistas e definitivas, sejam traçadas, requerendo uma análise dinâmica das inter-relações constatadas.
\end{abstract}

Palavras-chave: Êxodo Rural. Jovens. Irati/Guamirim.

\begin{abstract}
The current demographic context increased the importance of migration and showed the importance of population dynamics in their relationships with various aspects such as social, economic, political, cultural and even subjective, which call attention to the causes of rural exodus. Although theoretical studies
\end{abstract}

\footnotetext{
* Graduado em Administração e em Ciências Contábeis pela Universidade Estadual do Centro-Oeste. Especialista em Controladoria e Finanças. Acadêmico de Geografia - Licenciatura pela mesmo IES. E-mail: <andradeadm@yahoo.com.br>.

** Graduado em Geografia pela Universidade Estadual do Centro-Oeste (Unicentro). Mestre em Geografia "Gestão do Território" pela Universidade Estadual de Ponta Grossa (UEPG). Professor do Departamento de Geografia da Unicentro, campus de Irati-Pr. E-mail: <zaqueudegeo@yahoo.com.br>.
} 
point out to a quantitative decline in this type of migration, it still persists when considering certain population profiles. Therefore, this study aimed to check with students finishing high school at the "Colégio Estadual do Campo Nossa Senhora de Fátima", in the District of Guamirim in Irati- PR, which of the main factors driving migration engenders a more specific perspective to analyze the issue, revealing nuances attenuated in broader scale analyzes. The results obtained from the questionnaires administered to students suggest that for the specific case studied, variables such as the intention to continue studying, geographical location associated with the conditions of roads and transport and, labor supply have strong influence on migration dynamics. Other relevant factros can be understood as the background that comprise the context of the students and the place, such as cultural, ethnic, historical, and psychological factors or subjective, confirming the specificity and complexity the determinants of this dynamic, making it difficult to provide linear explanations of cause and effect, common and definitive. Thus, a dynamic analysis of the interrelationships found is necessary.

Keywords: Migration. Youth. Irati/Guamirim.

\section{Introdução}

As mudanças demográficas ocorridas nos últimos anos evidenciaram com maior nitidez os impactos decorrentes da migração. Entretanto, esse movimento populacional tem relações históricas e geográficas. Regiões como o Sul, na atualidade, têm no êxodo rural pequena importância no crescimento das cidades, conforme aponta Alves (2006).

Acredita-se, porém, que na escala específica do lugar (Guamirim), que se caracteriza como objeto do presente estudo, permanece a relevância da pesquisa, especialmente quando se abordam as perspectivas culturais, sociais, políticas e, como cita Damiani (2008), principalmente econômicas, tendo em vista que essa perspectiva demonstra a impossibilidade (temporária ou definitiva) de absorção de contingentes populacionais no mercado de trabalho ou de oferecer serviços e condições demandadas pela população.

Além disso, é necessário reputar a existência de fatores culturais e psicológicos que marcam as especificidades do local e integram a subjetividade de cada indivíduo, afetando suas percepções e decisões, evitando assim determinismos ou abordagens consideravelmente superficiais.

Embora haja outras, o Instituto Brasileiro de Geografia e Estatística - IBGE (2001) destaca que as abordagens teóricas que analisam o fenômeno migratório basicamente dividem-se nas abordagens neoclássico-funcionalista e estruturalista.
A visão estruturalista, segundo o IBGE (2011), é defendida por autores como Paul Singer, que considera o fenômeno migratório como de natureza social, respondendo aos imperativos social, econômico e político, portanto, resultado de um processo global de mudança. O enfoque funcionalista, segundo o IBGE (2011, p. 15), considera a motivação individual, estabelecida racionalmente após a análise do custo-benefício do movimento, portanto, sem abandonar os reflexos econômicos.

A partir da compreensão dos motivos que impulsionam a saída do jovem da localidade ou mesmo que incentivam a sua permanência, governo e sociedade podem aperfeiçoar suas diretrizes e ações em prol da melhoria das relações socioeconômicas e até políticas em âmbito regional. Dessa forma, torna-se relevante verificar, para o caso específico, quais os principais fatores que influenciam na migração dos jovens concluintes do ensino médio do Colégio Estadual do Campo Nossa Senhora de Fátima, no Distrito de Guamirim, em Irati-PR, abordando fatores das perspectivas teóricas estruturalista e funcionalista.

Para objetivar tal finalidade, tornou-se relevante investigar o perfil socioeconômico dos alunos pesquisados. Em associação, se verificou também as principais características sociais, econômicas, políticas e culturais da localidade. A partir dessa relação, apurou-se quantitativamente as intenções de migração (temporária ou permanente) na localidade 
junto aos pesquisados, assinalando, finalmente, as principais causas que impulsionam esta dinâmica.

A relevância de apreciar esta dinâmica com os concluintes do Ensino Médio se deu porque o segmento populacional dos jovens tem destaque no que se refere à migração. Para Camarano e Abramovay (2010, p. 7), "são cada vez mais os jovens que vêm deixando o meio rural e entre estes é preponderante a participação das mulheres", resultados que também são corroborados por Antico (1997).

Entretanto, tais dados são genéricos e passíveis de variações decorrentes das especificidades que constituem as características de cada lugar, e podem, em pesquisas regionais mais abrangentes, ser camuflados pelos dados médios, ficando determinadas nuances imperceptíveis.

Harmonizando a necessidade de resultados mais precisos e específicos com as possibilidades operacionais da pesquisa, optou-se por analisar uma localidade específica e uma população de perfil mais homogêneo. Além disso, Bilsborrow (1998 apud IBGE, 2011) argumenta que "a melhor maneira de se captar o fenômeno migratório seria por meio de pesquisas amostrais específicas".

Para concretizar o presente estudo, foram adotados procedimentos metodológicos como a utilização de pesquisa bibliográfica em artigos e livros, além de leis e coletas de dados na instituição escolar. O levantamento empírico se valeu de questionários contemplando quinze questões fechadas e duas abertas, ponderadas quantitativamente e interpretadas de forma descritiva, segundo a concepção de Andrade (1999).

Tais questionários foram aplicados aos alunos concluintes do Ensino Médio do Colégio Estadual do Campo do Distrito de Guamirim, residentes na área de abrangência do Distrito de Guamirim, determinada segundo os ditames da Lei Municipal no 2.164 de 21 de dezembro de 2004, a qual estabelece em seu artigo $9^{\circ}$, alínea b, que o Distrito de Guamirim

[...] compreende as localidades de Guamirim, Rio Corrente I e II, Rio Preto I e II, Guaçatunga, Água Clara, Cerro do Leão, Pirapó, Boa Vista do Pirapó, Empossados, Barra do Gavião, Governador Ribas, Faxinal dos Ferreiras, Taquari, Coloninha de Guamirim, Campina de Guamirim, Água Quente, Arroio Grande, Rio Corrente dos Cabral, Rio Corrente dos Pedroso.
Do total de 49 alunos que compõem turmas do terceiro ano do colégio, 27 foram pesquisados, pois além dos faltosos na ocasião alguns residem em localidades não pertencentes ao Distrito. Deve-se ressaltar que as considerações formuladas não têm a pretensão de ser aplicadas a outros casos ou realidades.

\section{Fundamentação teórica}

Segundo Damiani (2008), nos discursos sobre subdesenvolvimento até a década de 1960, enfatizava-se o crescimento vegetativo ${ }^{1}$ como processo de incremento demográfico, quando então a migração ganha ênfase.

Gonçalves (2001, p. 173), ao falar sobre as migrações, faz uma analogia que clarifica a complexidade do fenômeno e a multiplicidade de fatores que podem ocasioná-lo em determinado contexto histórico-geográfico:

As migrações costumam figurar como o lado visível de fenômenos invisíveis. Aparecem muitas vezes como a superfície agitada de correntes subterrâneas. Verdadeiros termômetros que, ao mesmo tempo, revelam e escondem transformações ocultas.

Damiani (2008) e Gonçalves (2001) defendem que a migração não corresponde somente ao deslocamento de pessoas, mas à propagação de determinado sistema econômico e estrutura social. Os deslocamentos de pessoas geralmente provocam ou decorrem de mudanças sociais, econômicas, políticas e culturais significativas, o que torna relevante conhecer a gravidade destas variáveis.

Desta forma, fica nítido que o processo de migração, especificamente o êxodo rural, pode ser impulsionado por diversas variáveis, ter amplos e diversos reflexos e envolver interesses contraditórios.

Conforme Damiani (2008) exemplifica, da mesma forma que grandes proprietários de terra podem se valer dos benefícios do maior volume de pessoas na área rural, inversamente podem induzir a migração ao substituírem o trabalho humano pelo mecanizado ou por meio de outras estratégias que favoreçam a concentração fundiária. Outro exemplo

\footnotetext{
${ }^{1}$ Diferença positiva entre a taxa de natalidade e a taxa de mortalidade.
} 
é o processo de mecanização e o êxodo rural, no que tange as suas determinantes. Enquanto algumas correntes teóricas defendem, de modo geral, que a mecanização é um dos fatores responsáveis pela redução da necessidade de trabalhadores rurais, outros autores apontam que a mecanização é uma resposta ao êxodo rural impulsionado por outras variáveis.

Camarano e Abramovay (1999, p. 10) assinalam, por exemplo, que a década de 1970 foi "a maior testemunha de que nem sempre o êxodo rural está associado à transformação na base técnica dos sistemas produtivos na agricultura". Um mercado de trabalho urbano em expansão, por exemplo, pode disparar tais mudanças.

Entretanto, para Antico (1997, p. 97), as explicações que analisam os movimentos migratórios, especialmente do tipo rural-urbano, sob um contexto histórico específico, sobretudo relacionado aos reflexos da industrialização, "perderam parte do potencial explicativo com as transformações do processo produtivo e da configuração dos espaços e da dinâmica urbana em geral", exigindo cautela nas abordagens elaboradoras sob este viés.

Embora se considerado de forma dicotômica o processo de migração rural-urbana tenha seu ponto de partida no meio rural, em uma visão sistêmica desponta uma gradação entre o rural e o urbano decorrente de uma simbiose de muitas atividades outrora específicas. Como destacado em Reis (2006), o processo não está isolado de suas relações com o urbano, visto que são realidades que não existiriam isoladamente.

Reis (2006) salienta ainda que no Brasil são diversos e complexos os problemas que surgem na tentativa de definir o que seja o rural e o urbano. Além da imprecisão na delimitação dos perímetros urbanos, há uma legislação que não atende às mudanças econômicas e socioespaciais que trouxeram novas funções ao rural.

Diante dessa dificuldade, Silva (1997) ameniza a problemática, destacando que a diferença entre o rural e o urbano é cada vez menos importante. Pode-se dizer que o rural integra, em algum ponto, o continuum teórico do urbano.

Entretanto, essas mudanças ocorrem não somente na lógica da produção e do consumo, mas apresentam aspectos multidimensionais, extrapo- lando os limites do econômico e até mesmo do social. Trazem também novas necessidades ao contexto rural, no sentido de proporcionar uma adaptação tanto do espaço quanto da população aos novos paradigmas.

Nessas circunstâncias, o Estado tem um papel de destaque, pois tais mudanças demandam políticas que tragam novos redirecionamentos econômicos, ambientais, sociais, que priorizem ou releguem a infraestrutura necessária às atividades vinculadas ao capital, interferindo no modo de vida da população.

A agricultura, por exemplo, realizada sob bases tecnológicas mais eficientes e melhor mecanizada, ao mesmo tempo integrada com a agroindústria, também é um fator que exerce influência, tanto como impulsionador da migração quanto como fator de permanência; traz, também, implicações nas relações de trabalho. Silva (1997, p. 25), por exemplo, em relação à política de emprego, destaca que

[...] o trabalho assalariado agrícola vem diminuindo rapidamente nos anos 90; e a ocupação em atividades agrícolas só não vem caindo mais rapidamente porque vem crescendo o número de pessoas que se dedicam a atividades agrícolas em tempo parcial e de autoconsumo, especialmente nos segmentos da agricultura familiar.

Por outro lado, a possível saída dessas pessoas do campo para a área urbana também contribuiu aos interesses do mercado, gerando suas consequências. Damiani (2008, p. 44) comenta que essa massa de trabalhadores disponíveis pressiona os salários dos que estão empregados de forma a não acompanhar proporcionalmente o incremento da produtividade.

Deve-se salientar que, para Silva (2001), dizer que atualmente o espaço rural brasileiro é agrícola é um mito, dado o crescimento de atividades assalariadas e a redução do emprego agrícola. Ao mesmo tempo, "a população residente no campo [...] parou de cair. Esses sinais trocados sugerem que a dinâmica agrícola, embora fundamental, já não determina sozinha os rumos da demografia no campo".

Camarano e Abramovay (2010, p. 7) acrescentam ainda uma nova perspectiva sobre o êxodo rural que deve ser considerada: o envelhecimento e a masculinização da população que vive no campo. Para eles, "são cada vez mais os jovens que vêm deixando o meio rural e entre estes é preponderante a participação das mulheres". 
Destarte, percebe-se que há uma complexidade de fatores apontados pelo referencial bibliográfico que podem ter influência nos processos migratórios. Mais que isso, a teoria referencia vastamente as contradições decorrentes dessa dinâmica, as quais extrapolam uma análise sob as dicotomias urbano e rural, sociedade e Estado.

O êxodo rural, nesse contexto, submete-se a desdobramentos que perpassam diversas perspectivas, impossibilitando explicações lineares de causa e efeito, requerendo uma análise dialética e dinâmica das inter-relações constatadas.

Como aduz Antico (1997, p. 112), "as questões ligadas à migração vêm adquirindo maior complexidade, à medida que o movimento e os perfis dos migrantes se diversificam", tanto em motivos quanto em características, o que torna interessante verificar a especificidade de cada caso em análises estratificadas e em escala geográfica menos abran- gente, almejando captar a complexidade ou influências de aspectos como a estrutura fundiária de determinada região, aspectos sociais, econômicos, culturais, políticos, ideológicos, além dos fatores subjetivos.

\section{O Distrito de Guamirim à luz de um enfoque geográfico}

Conforme a classificação do IBGE (2010), o território municipal de Irati localiza-se na mesorregião sudoeste do estado do Paraná. Dispõe de uma área territorial, segundo o Instituto Paranaense de Desenvolvimento Econômico e Social (IPARDES, 2011), de $995.289 \mathrm{~km}^{2}$ e atualmente é constituído por quatro distritos: Sede, Gonçalves Júnior, Itapará e Distrito de Guamirim, este delineado na pesquisa e ilustrado na figura a seguir.

Figura 1 - Distribuição dos distritos no município de Irati

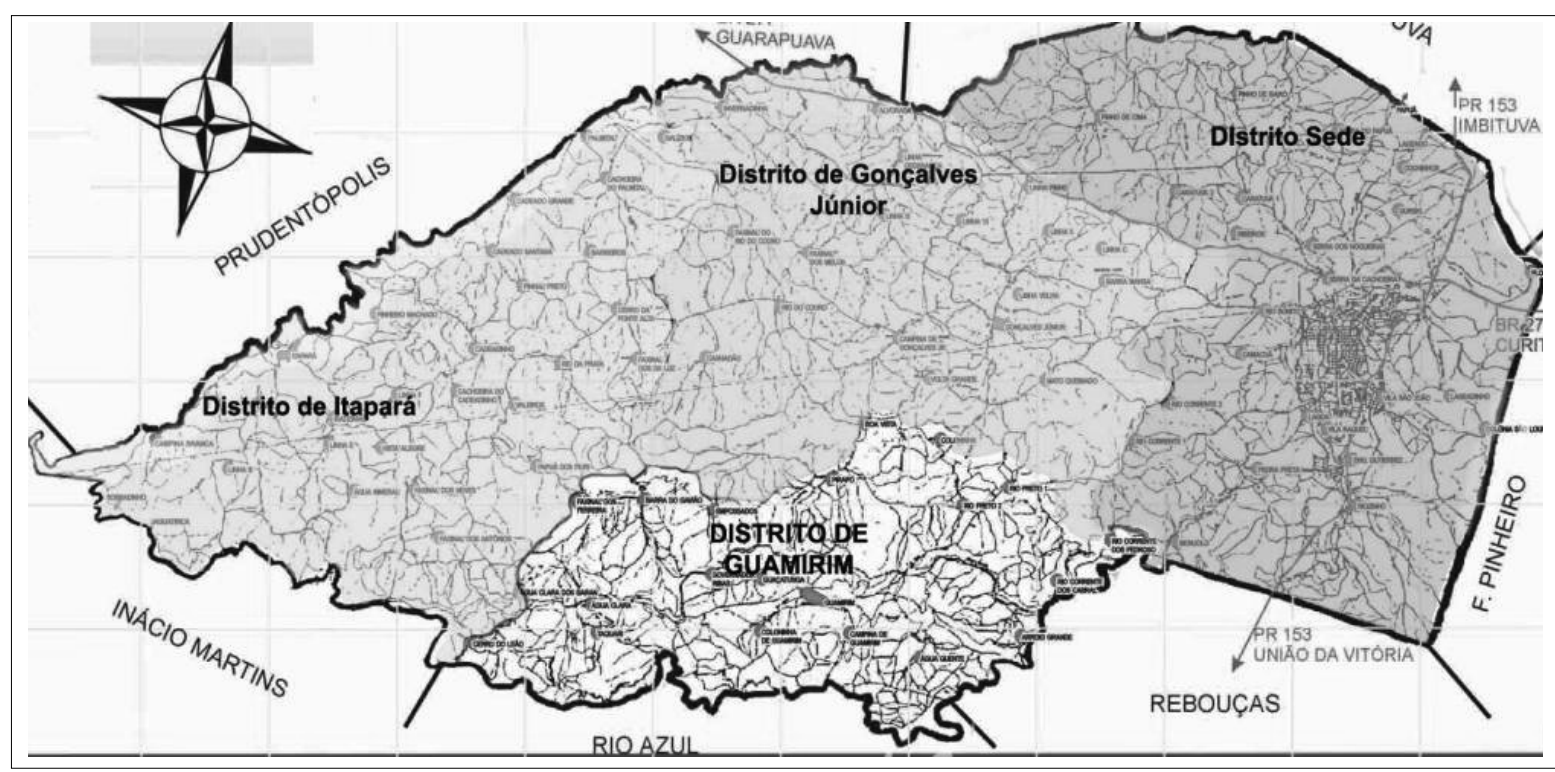

Fonte: Prefeitura Municipal de Irati adaptado com base na Lei Municipal no 2.164/04.

Segundo dados do IBGE (2010) e do IPARDES (2011), o território municipal iratiense apresenta uma densidade demográfica de 53,26 $\mathrm{hab} / \mathrm{km}^{2}$, com uma população de 56.207 habitantes. Destes, 44.932 residem na área urbana e 11.275 nas áreas rurais, expressando uma taxa de urbanização de aproximadamente $79,94 \%$.
O quadro seguinte apresenta as variações demográficas ocorridas nos últimos anos, no qual é possível perceber que em Irati ainda ocorre uma redução da população rural (uma variação percentual de mais de $13 \%$ nos últimos 10 anos) e um incremento da população urbana, diferente de outras regiões para as quais o referencial teórico apontou uma estagnação do êxodo rural. 
Quadro 1 - Variáveis demográficas no município de Irati

\begin{tabular}{c|c|c|c|c|c|c}
\hline \multirow{2}{*}{ ANO } & \multicolumn{2}{|c|}{ População Total } & \multicolumn{2}{c|}{ População Urbana } & \multicolumn{2}{c}{ População Rural } \\
\cline { 2 - 7 } & $\mathrm{N}^{\mathbf{o}}$ & $\%$ & $\mathrm{~N}^{\mathrm{O}}$ & $\%$ & $\mathrm{~N}^{\mathbf{0}}$ & $\%$ \\
\hline 2000 & 52.318 & $100 \%$ & 39.290 & $75,098 \%$ & 13.028 & $24,902 \%$ \\
\hline 2007 & 54.151 & $100 \%$ & 42.195 & $77,921 \%$ & 11.956 & $22,079 \%$ \\
\hline 2010 & 56.207 & $100 \%$ & 44.932 & $79,940 \%$ & 11.275 & $20,060 \%$ \\
\hline
\end{tabular}

Fonte: Prefeitura Municipal de Irati (2007), IBGE (2000, 2010).

Com relação aos aspectos étnico-culturais da população iratiense, segundo Fillos (2008, p. 23) há "uma mistura de raças [sic], uma vez que antes mesmo da emancipação política do município, imigrantes e descendentes iniciaram o processo de povoamento do território".

Segundo Menon (1993 apud Fillos, 2008, p. 23), quanto aos aspectos econômicos, a agricultura sempre manteve papel de destaque. Exemplificando, entre meados da década de 1920 até a década de 1940, eram cultivados em Irati 40\% do trigo paranaense e o município era o maior produtor de batata inglesa do país. Atualmente, predominam nas pequenas propriedades as culturas de cebola, milho, soja e feijão.

Há também o cultivo do fumo em diversas propriedades. Essa cultura, apesar das críticas, entre elas a monopolização do território e a absorção de grande parcela dos lucros por agentes externos, "ao garantir uma renda ao homem do campo [...] contribui para atenuar o êxodo rural" (NABOZNY; RODRIGUES, 2011, p. 5).

Para o IPARDES (2011), considerando o município como um todo, a soja, o milho e o feijão são os principais produtos agrícolas em termos de área colhida $(34,4 \%, 34 \%$ e $16,40 \%$ da área agrícola, respectivamente). Porém, quando se considera o valor monetário da produção, o fumo assume a segunda colocação, embora ocupe menos de $6 \%$ da área agrícola total.

Quanto aos aspectos fundiários no município e as condições dos produtores, dados do IPARDES (2011) revelam que a maioria dos estabelecimentos (78\%) é de propriedade dos próprios agricultores, respondendo por $89 \%$ da área agrícola do município. A condição de ocupante, apesar de expressiva numericamente, pode embutir em seus números agricultores que compartilham a propriedade com familiares. Quanto aos arrendatários (7\%), podem estar incluídos tanto aqueles que buscam nesta forma de relação ampliar temporariamente a área plantada quanto produtores sem a posse efetiva de terras.
Com relação especificamente ao Distrito de Guamirim, parte constituinte do "todo" territorial do município, segundo Orreda (2007), originou-se quando em 1839 duas bandeiras de Sorocaba chegaram ao local, fundando em 1904 o Distrito de Bom Retiro. Com a instalação da Estação Ferroviária Governador Manoel Ribas, há $3 \mathrm{~km}$ da sede do Distrito de Guamirim, os produtores rurais tiveram a possibilidade de escoar a produção, especialmente de batata inglesa, para um mercado mais abrangente. O nome Guamirim passou a vigorar em 1944, por decisão federal, a fim de evitar localidades com nomes idênticos.

Evidencia-se que no Distrito tem-se fixo o colégio estadual do campo "Nossa Senhora de Fátima". Segundo dados da Secretaria Estadual de Educação do Paraná (SEED), o colégio acima apontado contava, em 2012, com um total de 426 alunos matriculados do $6^{\circ}$ ao $9^{\circ}$ ano do Ensino Fundamental e do $1^{\circ}$ ao $3^{\circ}$ ano do Ensino Médio, além dos alunos nas salas multifuncionais e de atividade complementar.

O estudo em questão, ao propor destacar, a partir dos alunos concluintes do Ensino Médio que vivem no Distrito de Guamirim, os fatores influentes nos processos migratórios, identificou a existência de diversas variáveis dinâmicas e com reflexos distintos, conforme se dão as inter-relações com outros fatores contextuais.

Dada a impossibilidade de minuciar neste trabalho todos os resultados obtidos na pesquisa, especialmente quando se considera a influência das inter-relações de todas as especificidades existentes (geográficas, históricas, culturais e dos próprios indivíduos), serão traçadas, de forma genérica, as principais influências que pressionam os pesquisados a migrar, segmentadas, para fins didáticos (pois na prática o contexto é sistêmico), em análise do perfil dos alunos, características das propriedades rurais, questões socioeconômicas, para finalmente convergir às análises para os motivos que estimulam o pesquisado a migrar. 


\section{Análise do perfil dos alunos}

Embora a Lei Municipal no 2.164/04 cite que 23 localidades compõem o Distrito de Guamirim, a maioria dos alunos pesquisados reside nas localidades descritas no gráfico a seguir.

Gráfico 1 - Distribuição dos alunos pesquisados quanto à localidade de origem

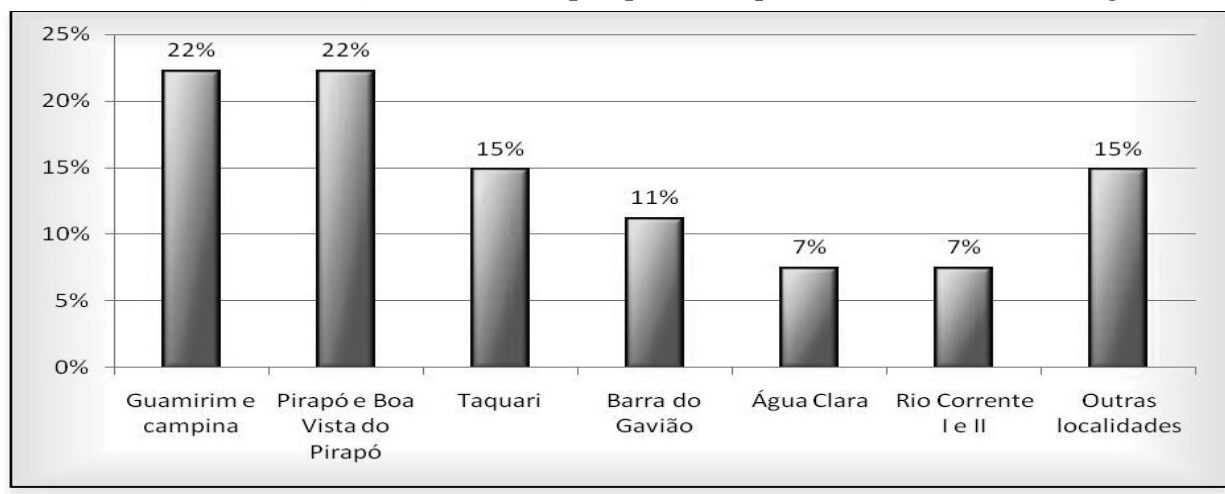

Fonte: Pesquisa de campo.

Na elaboração do gráfico, para fins de simplificação, localidades contíguas, como Guamirim e Campina, Pirapó e Boa Vista, e Rio Corrente I e II, foram agrupadas. As "outras localidades" (15\%) se referem a Empossados, Faxinal dos Ferreiras, Governador Ribas e Rio Preto. As demais não estão representadas na pesquisa.

Deve-se destacar que foram abordados os alunos concluintes do Ensino Médio. Nas outras turmas e séries pode haver preponderância de alunos de outras localidades. Entretanto, é preciso evidenciar que algumas localidades, como Guamirim e Campina de Guamirim, apresentam facilidades de acesso devido à proximidade com o colégio. Localidades como Rio Corrente, Rio Preto e Pirapó, embora exijam deslocamentos, por se localizarem próximas à rodovia (PR-364, que liga Irati a Inácio Martins) apresentam maiores facilidades de acesso ao transporte escolar, de forma diversa das dificuldades de outras localidades, especialmente nos dias de chuva.

Os dados ainda revelam que preponderam alunos concluintes do Ensino Médio do

gênero feminino, sendo apenas Fonte: Pesquisa de campo. $30 \%$ do sexo masculino. Esse deira e reflorestamento. resultado induz a refletir se tal fato decorre da predominância de mulheres nas localidades, portanto, uma questão demográfica, ou se exprime a maior inserção e continuidade do gênero feminino no campo educacional, ou, ainda, se está associado às questões socioeconômicas, como se os homens estão deixando o estudo e se dedicando às atividades profissionais no campo ou mesmo nas cidades, ou tendo mais faltas para auxiliar nos períodos de safra.

Quanto à idade, a pesquisa revelou que não há significativa distorção série/idade entre os alunos pesquisados, já que $84 \%$ dos alunos do $3^{\circ}$ ano têm entre 17 e 18 anos (nascidos em 1994 ou 1995).

\section{Características das propriedades rurais}

O questionário procurou patentear também de quais atividades as famílias dos alunos se ocupam em suas localidades. Os dados revelaram que $70 \%$ desempenham atividades relacionadas com a agricultura. Os 30\% restantes desenvolvem atividades classificadas na pesquisa como não agrícolas, como trabalho assalariado, construção, transporte de ma-

Ampliando a especificidade dos resultados, a questão seguinte quantificou as respostas segundo o tipo de atividade agrícola realizado pelas famílias.

Gráfico 2 - Tipo de atividade agrícola realizado na propriedade

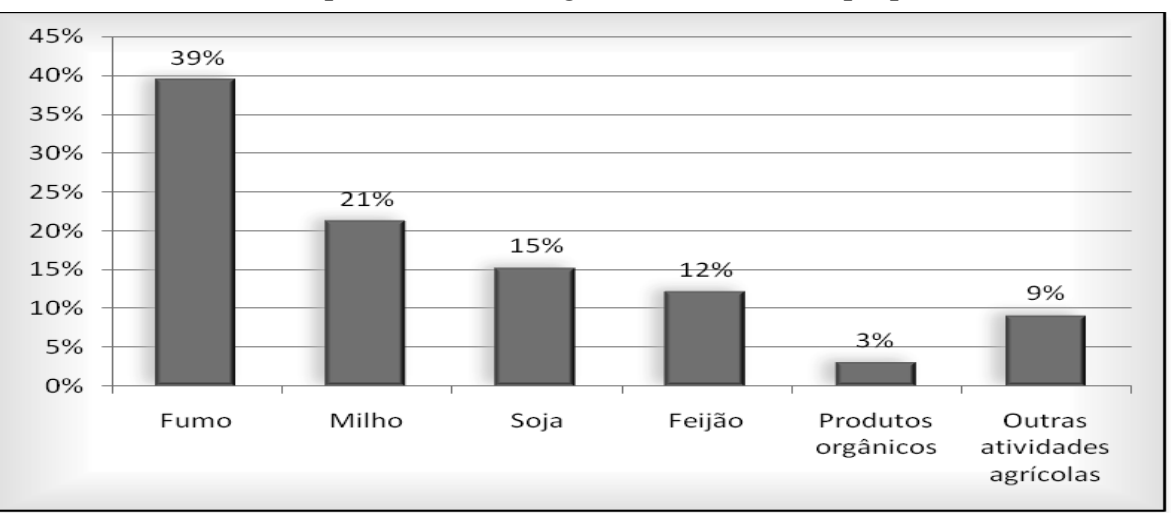


A predominância da cultura do tabaco no Distrito de Guamirim se coaduna com o que expressam Fillos (2008) e Nabozny e Rodrigues (2011), que defendem que o relevo acidentado do município é um dos fatores que contribui para a opção agrícola do plantio do fumo nas pequenas propriedades, o qual, relativamente a outras culturas, não exige máquinas e permite a utilização praticamente total do espaço disponível.

Ressalta-se que para o IPARDES (2011), no município, a soja, o milho e o feijão são os principais produtos agrícolas em termos de área colhida $(34,4 \%, 34 \%$ e $16,40 \%$ respectivamente). Porém, quando se considera o valor monetário da produção, o fumo assume a segunda colocação, perdendo apenas para o feijão, embora ocupe menos de $6 \%$ da área agrícola total.

Isto suscitou a verificar o tamanho relativo das propriedades na concepção dos pesquisados, tomando como base para a comparação a maioria das propriedades vizinhas do aluno.
Constata-se que embora exista um percentual significativo de propriedades consideradas menores, prevalece um equilíbrio na estrutura fundiária. É expressivo o número de pesquisados que não percebem a existência de grandes propriedades no entorno de onde residem, demonstrando uma baixa tendência de concentração fundiária.

Reforçando as inferências e eliminando algumas interpretações que não têm correlação entre si, relacionou-se o tamanho da propriedade com as principais atividades desempenhadas pela família dos pesquisados. Verifica-se que é nas propriedades classificadas como relativamente "um pouco maior" onde exclusivamente se desenvolvem atividades relacionadas com a produção orgânica. Também se destacam as culturas de soja e feijão.

Gráfico 3 - Tamanho relativo da propriedade na percepção dos pesquisados

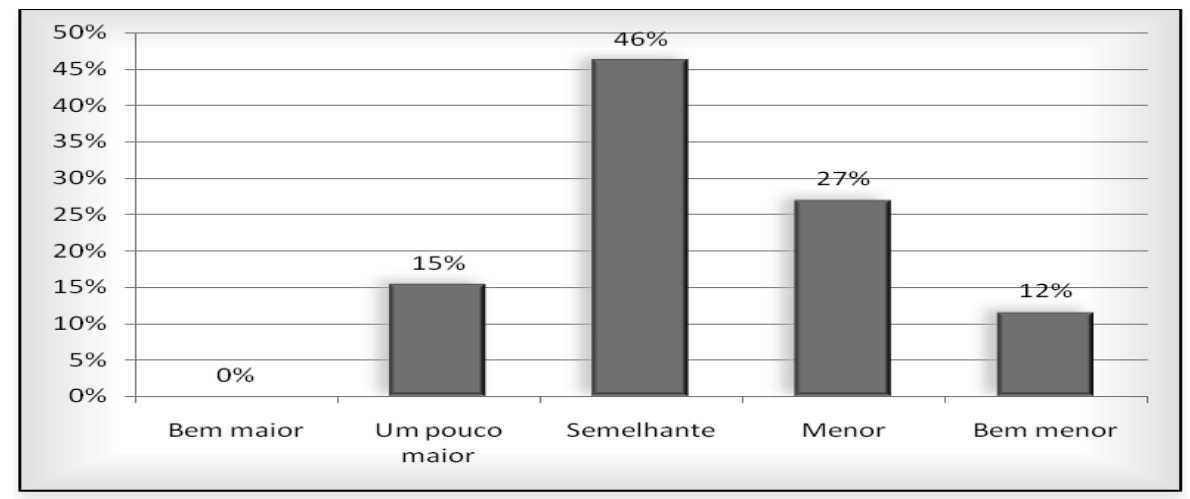

Fonte: Pesquisa de campo. 
Gráfico 4 - Relação entre tamanho da propriedade e atividade realizada

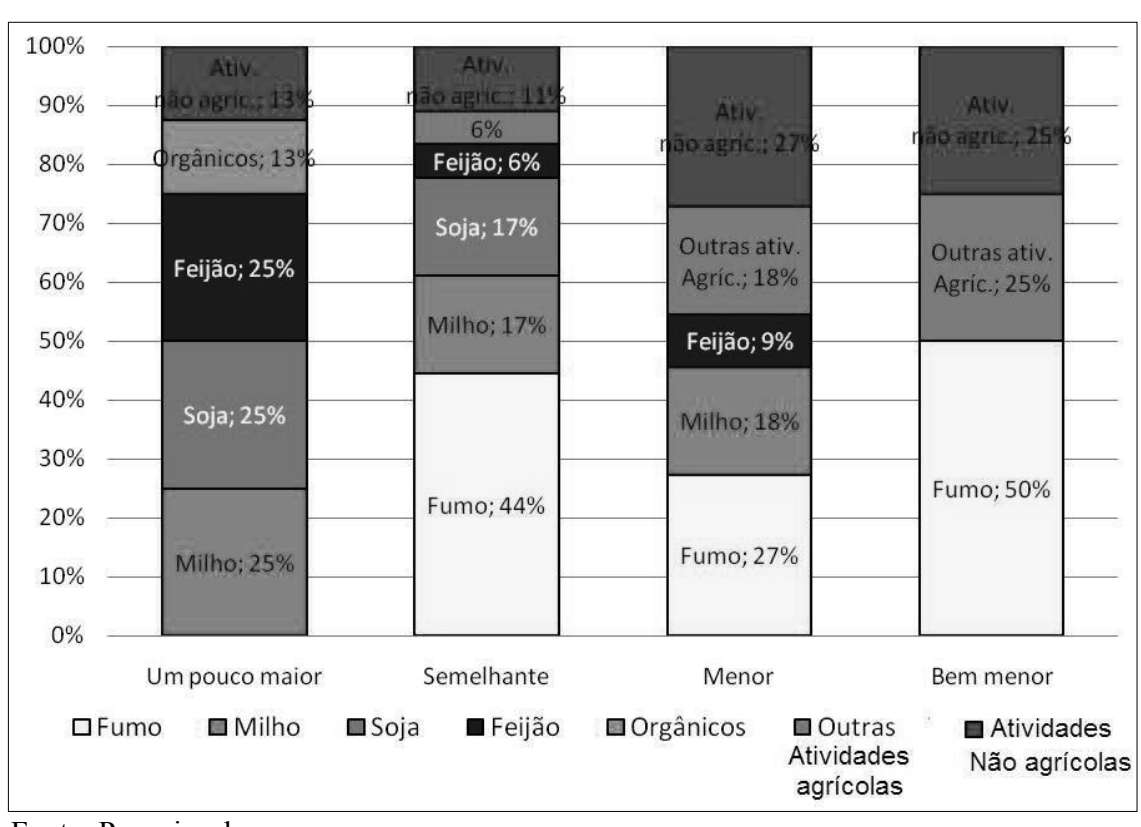

Sobre isso, destaca-se que na localidade de Guamirim, na qual está instalado o Colégio Estadual do Campo, além de uma escola rural de séries iniciais do Ensino Fundamental, onde há dois mercados, posto de saúde, farmácia, entre outros estabelecimentos, é maior o percentual de famílias de alunos que se dedicam principalmente a atividades não agrícolas.

Nas demais localidades, a atividade agrícola tem significativo destaque, sendo que em nenhuma delas o percentual de famílias está abaixo da média $(33,33 \%)$, merecendo destaque Barra do Gavião e Pirapó, com $67 \%$ e $63 \%$, respectivamente. Entretanto, a cultura do fumo também se destaca na maioria das localidades. Em Taquari, quase $70 \%$ dos pesquisados têm famílias que se dedicam à cultura do tabaco. Destacam-se também Rio Corrente $(50 \%)$ e Pirapó (38\%)

\section{Aspectos socioeconômicos}

A existência de uma parcela significativa de familiares que desenvolvem atividades não agrícolas, especialmente sob a forma assalariada e nas propriedades menores, justifica apresentar também a existência, na família dos pesquisados, de pessoas que trabalham de forma assalariada e de pessoas maiores de 18 anos em busca de ocupação profissional. Os dados obtidos com os questionários revelam que $41 \%$ dos pesquisados têm, em sua família, pessoas trabalhando externamente de forma assalariada. Quanto à existência de pessoas maiores de 18 anos em busca de ocupação profissional, $56 \%$ dos questionários confirmaram esta busca, demonstrando que o trabalho e a renda gerados pela propriedade não são suficientes para integrar todos os membros da família.

Obviamente, essa integração não pode ser interpretada simplesmente pelo viés econômico, já que diversas variáveis podem exercer influência na busca de ocupação, inclusive a escolaridade dos indivíduos, o número de pessoas na família, o tamanho da propriedade e o tipo de cultivo, 
especialmente quando se refere à cultura do fumo, como também o desejo pessoal de independência, revelando a subjetividade implícita na questão.

Relacionando os dados referentes à busca por ocupação profissional com o número de membros da família, os dados indicam que nas famílias com mais de cinco membros é que predomina a existência de pessoas buscando ocupação.

Porém, quanto ao número de membros da família ter uma correlação com o fato dos familiares dos pesquisados deixarem a localidade, não há consistência estatística nos dados para tal afirmativa. $\mathrm{O}$ cruzamento dos dados indica que o maior número de migrações de familiares ocorreu nas famílias de três a quatro membros; entretanto, este é o tamanho predominante das famílias (66,7\% dos pesquisados).

Quanto aos motivos da saída de familiares da localidade, a busca por emprego representa $58 \%$ das respostas de todos os pesquisados que tiveram casos de migração na família e a saída para estudar representa $26 \%$ deste total, indicando serem dois fatores sumamente importantes. Todavia, a busca por emprego prevalece nas propriedades menores.

\section{Fatores que influenciam a migrar}

Especificando as razões que podem impulsionar os pesquisados a migrar, o questionário contemplou a seguinte pergunta: Pretende continuar estudando após a conclusão do Ensino Médio?

A maioria dos pesquisados (81\%) pretende continuar estudando, $15 \%$ não pretendem e $4 \%$ ainda definirão a escolha. Tendo em vista que após o Ensino Médio as possibilidades na localidade atualmente são nulas, esses alunos dependerão de locomoção diária ou de residir na área urbana para dar continuidade aos estudos.

Relacionando essa questão com o gênero do aluno, evidencia-se que os pesquisados do sexo feminino apresentam as maiores intenções de continuar estudando. Com relação aos pesquisados que não querem prosseguir com os estudos, a variação percentual é de $138 \%$ entre mulheres e homens. Apenas $10,5 \%$ delas não querem continuar estudando e, entre eles, $25 \%$ pretendem findar sua escolaridade ao término do Ensino Médio.

Complementando essa questão, os dados revelaram que $100 \%$ dos pesquisados que continuarão seus estudos pretendem mudar sozinhos para a área urbana, evidenciando a necessidade de qualificação e de estudo como um relevante fator de influência na migração dos jovens para a área urbana.

Como não se pode afirmar que a busca por estudo é a única ou mesmo a principal variável capaz de impelir estes jovens a mudar, verificou-se se há motivos ou não para migrar em relação ao tamanho da propriedade familiar.

Os dados mostraram que, à medida que diminui a classificação do porte relativo da propriedade, eleva-se o percentual de pesquisados que apresentam motivos para deixar a comunidade. Nas propriedades "um pouco maiores", nenhum pesquisado apresentou motivos para migrar. Nas propriedades de tamanho "semelhante" às do entorno, $58 \%$ apresentaram razões para o êxodo. Nas propriedades "menores" e "bem menores", 100\% dos pesquisados apresentaram razões para deixar a localidade, indicando ser uma variável significativa.

O Coeficiente de Correlação de Pearson, aplicado às variáveis "tamanho da propriedade" e "percentual de alunos que diz ter motivos para mudar", apresenta um $\mathrm{R}^{2}$ de 0,93 , indicando uma forte correlação estatística entre estas variáveis.

Considerando a existência de questões pontuais ou específicas em cada localidade pertencente ao Distrito de Guamirim, correlacionou-se também a "existência de motivos que impulsionam a migrar" com a localidade dos pesquisados. Os dados evidenciaram uma dispersão das respostas, tanto afirmativas quanto negativas, em todas as localidades, indicando que os fatores que estimulam os pesquisados a migrar para a área urbana existem em todas as localidades do Distrito, indicando uma questão regional mais abrangente, como fatores sociais, políticos, econômicos etc. ou mesmo um fator subjetivo ou cultural, especialmente relacionado à idade e escolaridade dos alunos.

O questionário também contemplou um conjunto de perguntas abertas. Nelas os pesquisados deveriam expor os pontos positivos e negativos, as vantagens e desvantagens de residir na localidade. $\mathrm{O}$ gráfico abaixo demonstra, quantitativamente, essas respostas. 
Gráfico 5 - Síntese dos fatores positivos e negativos apontados pelos alunos pesquisados

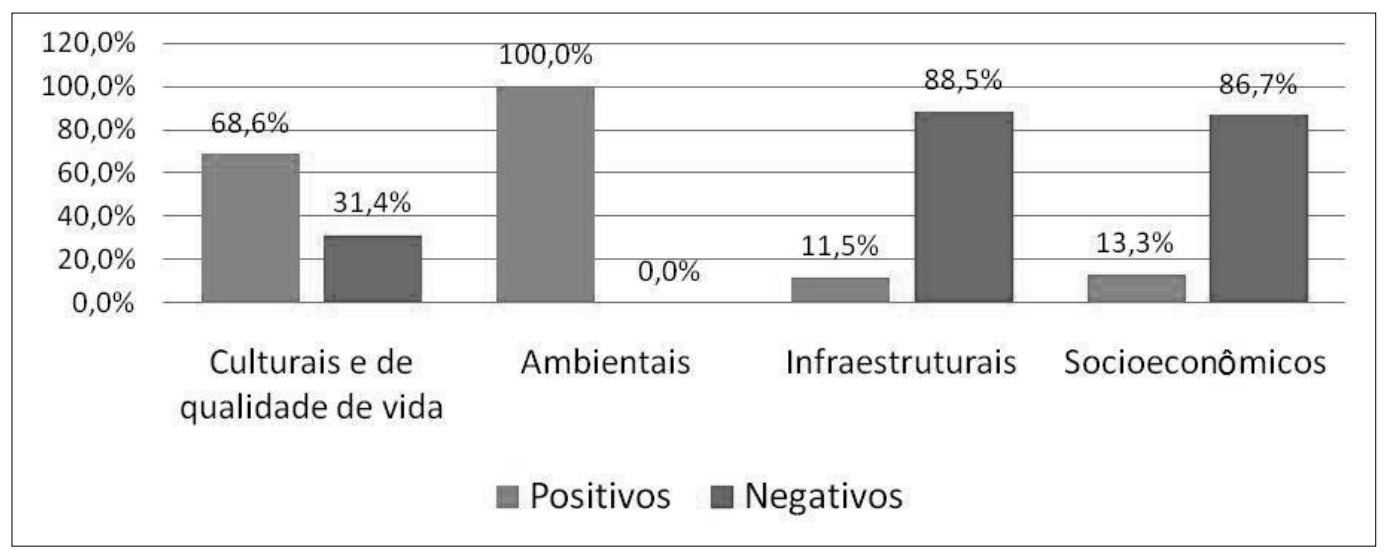

Fonte: Pesquisa de campo.

Embora arbitrariamente, as respostas mais recorrentes foram classificadas em quatro grupos de aspectos. Os grupos aspectos culturais e de qualidade de vida e aspectos ambientais não se mostraram como forças influentes na migração, ao contrário neles se destacaram respostas como a religiosidade, solidariedade, sensação de segurança, natureza e o convívio familiar. Entretanto, tais fatores referemse muito mais à individualidade e ao modo de vida de cada estudante, relacionando-se, inclusive, com a identidade com o lugar. Além disso, como explica Santos (2004, p. 40), "valores culturais não constituem, em si mesmos, a explicação de fenômeno algum; são antes fenômenos que devem ser explicados".

Quanto aos aspectos socioeconômicos e político-estruturais, vastas críticas referem-se à péssima conservação das estradas, à deficiência dos transportes e dos setores de saúde, à dificuldade de comunicação, de manter e continuar a escolaridade e de obter trabalho. Mencionou-se positivamente a proximidade (de algumas localidades) da área urbana, menor custo de vida e o lazer, como campos de futebol, rio etc.

Tais fatores em sua maioria são dependentes de ações materiais, como investimentos em obras públicas, bem como o atendimento de determinadas necessidades percebidas pela população. Portanto, justificam uma ação harmônica do Estado com as demandas sociais, destacando a influência do poder público, mesmo que indiretamente, como um dos fatores influentes na decisão dos estudantes pesquisados em migrar. Alerta-se, entretanto, que tais fatores não são estanques, mas inter-relacionados.

\section{Considerações finais}

A presente investigação objetivou precipuamente elencar os principais fatores que influenciam na permanência ou migração dos jovens concluintes do Ensino Médio do Colégio Estadual do Campo Nossa Senhora de Fátima, no Distrito de Guamirim, em Irati-PR, para a área urbana.

Para chegar ao objetivo geral proposto, tornou-se necessário verificar as principais características sociais, econômicas, políticas e culturais da localidade através da fundamentação teórica e ponderar a relação que tal questão mantém com o perfil socioeconômico dos alunos pesquisados.

Os dados revelaram que a maioria dos pesquisados advém das localidades de Guamirim, Campina de Guamirim, Pirapó, Boa Vista e Taquari, tornando os dados referentes a estas localidades mais consistentes.

A análise também revelou que as famílias dos pesquisados são compostas predominantemente por três a quatro membros. Tais famílias se dedicam, principalmente, às atividades agrícolas, com destaque para a importância da cultura do tabaco, em especial nas propriedades menores.

De modo geral, a estrutura fundiária do Distrito não apresenta graves distorções. Dessa forma, o tamanho relativo das propriedades não se constitui, de per si, em pressão para os jovens deixarem a localidade em que residem; porém, é preciso integrar a esta relação o tamanho das famílias e a necessidade de mão de obra na cultura agrícola predominante (tabaco). Pode-se se dizer, no entanto, que o tamanho da propriedade exerceu influência na migração dos familiares dos pesquisados. 
Associado ao tamanho da propriedade está o tipo de cultivo agrícola. Embora nas propriedades menores, onde há maior tendência ao êxodo, predomine o cultivo do fumo, e tendo em vista as características desta cultura em termos de necessidade de mão de obra, não se pode afirmar que isoladamente ela seja vista como a variável de destaque no êxodo rural. Isto porque até mesmo na localidade do Guamirim, a qual, entre todas as outras do Distrito, é a que mais se dedica às atividades não agrícolas, é significativo o percentual de interessados em migrar.

Entre os fatores que despertam a atenção pela significância das respostas como influente na migração aparece a intenção de continuar estudando, com leve predominância das mulheres. Considerando que no Colégio Estadual do Campo Nossa Senhora de Fátima só há a oferta até o Ensino Médio, as possibilidades de permanecer no local praticamente se excluem. Este seria o fator a priori impulsionador do êxodo. Entretanto, em muitas localidades, poderia haver a possibilidade de os alunos se deslocarem diariamente para a sede do município. Entretanto, essa alternativa depende da possibilidade de transporte público nos dias e horários adequados ou condições financeiras para suportar o transporte particular. Assim, despontam duas variáveis: o transporte escolar e a localização geográfica, já que esta influencia na oferta e no custo daquele.

Considerando que houve má avaliação das condições das estradas, do transporte coletivo, associado à distância desprivilegiada de algumas localidades da sede do município e dos serviços demandados (entre eles a possibilidade de continuar estudando por meio de deslocamentos diários), tal fator se torna importante como impulsionador das migrações para a área urbana.

Assim, percebe-se grande influência do Estado, mesmo que indiretamente, como força impulsionadora influente na migração, pois embora a necessidade ou desejo de escolaridade seja uma variável de grande força e destaque para o perfil pesquisado, isto poderia ser auferido sem o êxodo da localidade caso existissem melhores condições das estradas, maiores opções de transporte público ou mesmo a oferta de novas modalidades de ensino, atenuando, inclusive, os reflexos da localização geográfica mais distante da área urbana ou dos serviços demandados.
Pesa ainda a necessidade de trabalho. Mesmo nos lugares em que há melhores condições estruturais, muitos familiares dos pesquisados já deixaram a localidade em busca de ocupação. Isto mais uma vez reforça a necessidade de políticas públicas que garantam a fixação das pessoas no campo, já que na cidade as perspectivas socioeconômicas se mostram pouco atrativas.

Considerando a interdependência entre esses fatores, maiores investimentos no campo possibilitariam, além da permanência do jovem qualificado no campo, incentivos para que atividades agroindustriais se instalassem nas regiões e, consequentemente, existissem serviços demandados pela sociedade.

\section{Referências}

ALVES, Eliseu. Migração rural-urbana. In ALVES, Eliseu. Migração rural-urbana, agricultura familiar e novas tecnologias. EMBRAPA. Brasília: 2006. Disponível em: $<$ http://www.embrapa.br/publicacoes/institucionais/titulosavulsos/migracaorural-urbana.pdf $>$. Acesso em: 15 de março de 2012.

ANDRADE, M. M. Introdução à metodologia do trabalho científico. 4. ed. São Paulo: Atlas, 1999.

ANTICO, Claudia. Por que migrar? In: PATARRA, Neide; et. al. (org.). Migrações, condições de vida e dinâmica urbana: São Paulo, 1980-1993. Unicamp. Campinas: 1997. p. 97-114.

CAMARANO, Ana Amélia; ABRAMOVAY, Ricardo. Êxodo rural, envelhecimento e masculinização no Brasil: panorama dos últimos 50 anos. IPEA - Instituto de Pesquisa Econômica Aplicada. Rio de Janeiro: 1999. Disponível em: $<$ http://www.ipea.gov.br/portal/index.php?option $=$ com content\&view $=$ article\&id=3929 > . Acesso em: 14 de março de 2012.

DAMIANI, Amélia Luísa. População e geografia. 9. ed. São Paulo: Contexto, 2008.

FILLOS, Leoni Malinoski. A educação matemática em Irati (PR): memória e história: (dissertação). UFPR. Curitiba: 2008. Disponível em: <http://www.ppge.ufpr.br/teses/ M08_fillos.pdf $>$. Acesso em: 17 de março de 2012.

GONÇALVES, Alfredo José. Migrações internas: evoluções e desafios. Instituto de Estudos Avançados da Universidade de São Paulo. v. 15. n. 43, São Paulo: 2001. Disponível em: <http://www.scielo.br/pdf/ea/v15n43/ v15n43a14.pdf>. Acesso em: 23 de março de 2012.

IBGE - Instituto Brasileiro de Geografia e Estatística. Estimativa populacional de Irati (2010). Disponível em: $<$ http://www.ibge.gov.br/home/estatistica/populacao/ projecao_da_populacao/>. Acesso em: 24/3/2012. 
IBGE - Instituto Brasileiro de Geografia e Estatística. Reflexões sobre os deslocamentos populacionais no Brasil. Rio de Janeiro: 2011. Disponível em: <http:// www.ibge.gov.br/home/estatistica/populacao/reflexoes deslocamentos/deslocamentos.pdf>. Acesso em: 24/3/2012.

IPARDES - Instituto Paranaense de Desenvolvimento Econômico e Social. Caderno Estatístico Município de Irati. Novembrode2012.Disponívelem: $<$ http://www.ipardes.gov. br/cadernos/Montapdf.php?Municipio $=84500 \& \mathrm{btOk}=\mathrm{ok}>$. Acesso em: 29 de junho de 2012.

JACOBY, Carla et. al. Plantas medicinais utilizadas pela comunidade rural de Guamirim, Município de Irati, PR. Universidade Estadual do Centro-Oeste. Revista Ciências Exatas e Naturais: Vol. 4, $\mathrm{n}^{\mathrm{o}}$ 1, Jan/Jun 2002. Disponível em: <revistas.unicentro.br/index.php/R ECEN/arti cle/ viewArticle/470>. Acesso em: 21 de junho de 2012.

NABOZNY, Almir; RODRIGUES, Danilo. Associativismo rural: avanços e retrocessos no desenvolvimento socioespacial na Comunidade de Guamirim - Irati/ PR. Campo Território: Revista de Geografia Agrária, v. 6, n. 12, p. 264286, ago., 2011. Disponível em: <http://www.seer.ufu.br/ index.php/campoterritorio/article/view/12004>. Acesso em: 3 de junho de 2012 .

ORREDA, José Maria. Revista do Centenário: História. v. 8. Irati: 2007. O Debate.

SANTOS, Regina Bega dos. Movimentos sociais urbanos. São Paulo, 2004. Ed. UNESP. Série Poder.

SEED. Secretaria de Estado da Educação. Consulta Escolas. 2012. Disponível em: $<$ http://www4.pr.gov.br/escolas/ frmPesquisaEscolas.jsp>. Acesso em: 21 de junho de 2012.

Resolução n. 2012 de 14 de maio de 2012.

SILVA, José Graziano da. O novo rural brasileiro. Revista Nova Economia. Belo Horizonte. 1997. Disponível em: $<$ http:/www.geografia.fflch.usp.br/graduacao/apoio/Apoio/ Apoio_Va leria/Pdf/O_novo_rural_brasileiro.pdf $>$. Acesso em: 21 de março de 2012 .

SILVA, José Graziano. Velhos e novos mitos do rural brasileiro. Estudos avançados. n. 15. v. 43. São Paulo: 2001. Disponível em: <http://www.scielo.br/scielo.php?script= sci_arttext\&pid=S0103-40142001000300005>. Acesso em:

17 de julho de 2012 .

Data de Submissão: outubro de 2012

Data de Aprovação: março de 2013 
